\title{
HfN nanoparticles: an Unexplored Catalyst for the Electrocatalytic Oxygen Evolution Reaction
}

\author{
Chiara Defilippi ${ }^{[a]}$, Dipak V. Shinde ${ }^{[b]}$, Zhiya Dang ${ }^{[b]}$, Liberato Manna ${ }^{[b]}$, Christopher Hardacre ${ }^{[c]}$, Adam J. \\ Greer $^{[\mathrm{c}]}$, Carmine D’Agostino ${ }^{[\mathrm{c}]}$ and Cristina Giordano ${ }^{[\mathrm{a}] *}$
}

\begin{abstract}
Water electrolysis is one of the most promising methods to produce $\mathrm{H}_{2}$ and $\mathrm{O}_{2}$ as high potential fuels. Comparing the two halfreactions, the Oxygen Evolution Reaction (OER) is the more difficult to be optimized and still relies on expensive noble-metal based catalysts such as Ru or Ir. In this paper, we prepared nanoparticles of $\mathrm{HfN}$ and $\mathrm{Hf}_{2} \mathrm{ON}_{2}$ and tested them for the OER for the first time. The $\mathrm{HfN}$ sample, in particular, showed the highest activity, requiring an overpotential of only $358 \mathrm{mV}$ at $10 \mathrm{~mA} / \mathrm{cm}^{2}$ in Fe-free electrolyte and, above all, exhibiting long-term stability. This result places this system amongst one of the most promising catalysts for OER tested to date, in term of sustainability, activity and stability. The prepared nanoparticles are small (less than $15 \mathrm{~nm}$ in diameter), well-defined in shape and crystalline, and were characterised before and after electrochemical testing also via electron microscopy (EM), Powder Xrays diffraction (PXRD) and X-rays photoelectron-spectroscopy (XPS)
\end{abstract}

\section{Introduction}

Energy production is fundamental to modern society, which relies on it to survive and develop. Current energy production almost entirely relies on burning fossil fuels, which are no longer a sustainable solution. Among reliable alternatives, the production of high potential combustibles (such as $\mathrm{H}_{2}$ ) via electrolysis of water (Scheme 1) is one of the most promising methods.

$2 \mathrm{H}^{+}{ }_{(\mathrm{aq})}+2 \mathrm{e}^{-} \rightarrow \mathrm{H}_{2(\mathrm{~g})}$ at the cathode, $\mathrm{E}^{0}=0 \mathrm{~V}$,

HER (Hydrogen Evolution Reaction)

$\mathrm{H}_{2} \mathrm{O}_{(\mathrm{l})} \rightarrow 1 / 2 \mathrm{O}_{2(\mathrm{~g})}+2 \mathrm{H}^{+}{ }_{(\mathrm{aq})}+2 \mathrm{e}^{-}$at the anode, $\mathrm{E}^{0}=1.23 \mathrm{~V}$, OER (Oxygen Evolution Reaction)

$\Delta \mathrm{G}_{\mathrm{H}}=273.1 \mathrm{KJ} / \mathrm{mol}(1.23 \mathrm{~V})$ in standard condition

Scheme 1. The two half-reactions for the water-splitting: $\mathrm{H}_{2}$ is produced at the cathode (HER) and $\mathrm{O}_{2}$ at the anode $(\mathrm{OER})^{[1]}$.To ensure an efficient conversion, the process of water splitting requires the use of suitable catalysts, which are, to date, mainly based on noble

[a]School of Biological and Chemical Sciences, Chemistry Department, Queen Mary University of London, Mile End Road, London E1 4NS, United Kingdom

[b]Nanochemistry Department, Istituto Italiano di Tecnologia, via Morego 30,16163 Genova, Italy

[c] School of Chemical Engineering and Analytical Science, The University of Manchester, The Mill, Sackville Street, Manchester M13 9PL, United Kingdom

*c.giordano@qmul.ac.uk

Supporting information for this article is given via a link at the end of the document metals (Pt for HER and $\mathrm{IrO}_{x}$ or $\mathrm{RuO}_{x}$ for OER ${ }^{[1,2]}$ ), because they offer a lower overpotential $(\eta)$ compared to other materials and fast kinetics for driving the reaction. While Pt shows ideal activity for HER (close to zero overpotential in acidic conditions), there are no other catalysts that can catalyze OER at such low overpotentials. For example, even the most commonly employed $\mathrm{RuO}_{x}$ and $\mathrm{IrO}_{x}$ catalysts perform at overpotentials of a few hundred millivolts ${ }^{[3]}$. In this respect, OER is more difficult to be optimized compared with HER and despite extensive research, the overpotentials required to sustainably drive the OER are still very high. This has wide reaching implications considering that OER finds broader applications, e.g. in fuel cells and batteries ${ }^{[4]}$. One fundamental step to be considered for a sustainable and large-scale production of hydrogen from water splitting, besides optimising catalytic activity, is to explore readily available and cost-effective catalysts. Stability is also a key prerequisite and the ideal catalyst must be resistant under the reaction conditions, i.e. it should not undergo passivation or deactivation, and must possess high surface area, conductivity and homogeneity, to ensure an efficient electron transport.

With this aim, several classes of materials based on non-noble metals have been explored, including their alloys (e.g. Ni-Mo $)^{[5,6]}$, oxides and chalcogenides ${ }^{[1,7]}$, and in very few cases metal carbides $(\mathrm{MC})$ and nitrides $(\mathrm{MN})^{[1,7-9]}$. Among these compounds, MN possesses the highest electronic conductivity and stability under harsh conditions ${ }^{[1]}$. MN, as well as MC, are part of the family of metallic ceramics and possess high thermal and chemical resistance, good mechanical properties and high melting point, alongside metallic behaviour (e.g. good electronic conductivity) and obviously catalytic activity. The catalytic activity of some metallic ceramics is similar to that of some noble metals ${ }^{[10]}$ and some of them were found to be active not only for HER (e.g. $\mathrm{Mo}_{2} \mathrm{C}^{[11]}, \mathrm{Mo}_{2} \mathrm{~N}^{[12]}$ and $\mathrm{Co}_{x} \mathrm{~N}^{[13]}$ ) or OER (e.g. $\mathrm{Ni}_{x} \mathrm{~N}$ and $\mathrm{Fe}_{x} \mathrm{~N}^{[13-15]}$, Co $\mathrm{N} \mathrm{N}^{[1]}$ and $\mathrm{Mn}_{3} \mathrm{~N}_{2}{ }^{[16]}$ ), but also for the reverse electrochemical processes such as oxygen reduction reaction (ORR), the cathode reaction in the fuel cells $\left.{ }^{[17-19]}\right)$. In some cases, however, the material is unstable or the syntheses requires toxic ammonia flow, hindering the production on a large scale. Among metal nitrides, $\mathrm{Hf}$-based nitrides are one of the less explored in catalysis and electrocatalysis. So far, only HfON has been tested with promising results towards ORR ${ }^{[19,20]}$ and $\mathrm{HER}^{[21]}$, but not in OER. To the best of our knowledge, no studies on hafnium nitride $(\mathrm{HfN})$ have been reported. This is surprising considering that $\mathrm{HfN}$ is also a metallic ceramic with high melting point $\left(>3300^{\circ} \mathrm{C}\right)$ and low electrical resistivity $\left(27 \mu \Omega^{*} \mathrm{~cm}\right)^{[22]}$. Furthermore, it is expected to have chemical and physical properties similar to Zr-based materials, which was recently addressed as a high performing electrocatalyst from theoretical studies ${ }^{[23]}$. In addition, $\mathrm{Hf}$ is readily available and more abundant than $\mathrm{Ru}$ and Ir. For example, the price of $\mathrm{Hf}$ in 2010 was $\$ 563$ per kilogram ${ }^{[20]}$, while $\mathrm{Ru}$ was $8500 \$$ per kilogram and Ir is $47500 \$$ per kilogram ${ }^{[24]}$. One of the 
reasons behind the lack of studies for $\mathrm{HfN}$ might be related to the synthetic challenge related to its nanoparticles preparation. In fact only works on HfN films (using CVD and ALD) are known ${ }^{[25]}$ and no reports have been published on the formation of nanoparticles or nanofibers. Although useful for film preparation, neither ALD nor CVD allows large-scale productions. In this contribution, we present a sustainable synthesis of both $\mathrm{HfN}$ and $\mathrm{Hf}_{2} \mathrm{ON}_{2}$ nanoparticles and related application for the OER. The sol-gel based procedure used (known as Urea-Glass-Route, UGR) ${ }^{[26,27]}$ allows the easy preparation of both the metal oxynitride $\left(\mathrm{Hf}_{2} \mathrm{ON}_{2}\right)$ and the pure nitride phase $(\mathrm{HfN})$ in form of well-defined and small particles (15 and $10 \mathrm{~nm}$ for $\mathrm{Hf}_{2} \mathrm{ON}_{2}$ and $\mathrm{HfN}$, respectively), with relatively high surface area $\left(>40 \mathrm{~m}^{2} / \mathrm{g}\right)$. The change in composition is accompanied by a reduction of particles size, while reaction conditions (such as temperature and metal/urea molar ratio, $R$ ) have a significant effect on the morphology of the final material. Electrochemical tests have shown significantly improved performance using $\mathrm{HfN}$ over $\mathrm{Hf}_{2} \mathrm{ON}_{2}$ and $\mathrm{HfO}_{2}$ with an overpotential of $391 \mathrm{mV}$ at $10 \mathrm{~mA} / \mathrm{cm}^{2}$ and a Tafel slope of 94 $\mathrm{mV} / \mathrm{dec}$ in Fe-free $1 \mathrm{M} \mathrm{NaOH}$ electrolyte. Long-term chronopotentiometry tests (up to $24 \mathrm{~h}$ ) evidence good stability of the catalyst. These results place HfN amongst the best OER noble metal-free and iron contamination-free electro-catalysts tested so far. To the best of our knowledge, this is the first time that $\mathrm{HfN}$ and $\mathrm{Hf}_{2} \mathrm{ON}_{2}$ were prepared at the nanoscale and tested for OER.

\section{Results and Discussion}

Phase attribution on all prepared samples was ascertained by XRD analysis. Figure 1 shows the XRD patterns of samples prepared at different ratios and heat treatments. The pattern nicely matches that of expected $\mathrm{Hf}_{2} \mathrm{ON}_{2}$ for samples prepared with a urea/metal molar ratio $\mathrm{R} \leq 3$, and $\mathrm{HfN}$ for samples prepared with ratios $R>10$. This difference in composition is also reflected by a difference in colour (as shown in the experimental part): light grey for the oxy-nitride phase and darker grey for the nitride.
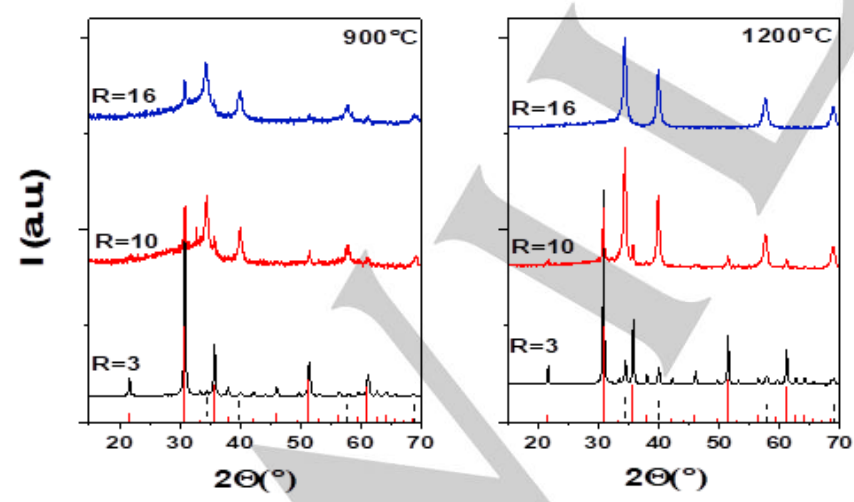

Figure 1. XRD patterns of samples prepared with different molar ratios $(R=3$, 10 and 16) and treated at $900^{\circ} \mathrm{C}$ (left) and $1200^{\circ} \mathrm{C}$ (right), respectively. The reference pattern of $\mathrm{Hf}_{2} \mathrm{ON}_{2}$ (ICDD: 00-050-1171, red vertical lines) and $\mathrm{HfN}$ (ICDD: 03-065-5056, dashed black lines) are also reported for comparison.
The possibility to address the synthesis to metal nitride over the metal oxynitride phase by changing $R$ and/or reaction temperature is a peculiarity of the UGR and was also observed for other systems ${ }^{[28,29]}$. The reaction temperature not only affects the crystallinity of the final material but also the purity. For samples treated at $\mathrm{T}=900^{\circ} \mathrm{C}$, traces of $\mathrm{HfN}$ can be observed in the $\mathrm{Hf}_{2} \mathrm{ON}_{2}$ phase, and vice versa, while a higher reaction temperature $\left(T=1200^{\circ} \mathrm{C}\right)$ leads to pure $\mathrm{HfN}$. The absence of the main graphitic peak from XRD pattern (expected around 26 degrees ${ }^{[30]}$ ) confirms the amorphous nature of the residual carbon observed from elemental analysis (Table 1). In all cases this was not found to be detrimental for the electrochemical performance of the active Hf-based material. The results of elemental analysis reported in table 1 also show a slight nitrogen deficiency in the $\mathrm{HfN}$ samples (wt $\%<6 \%$ ), compared to the theoretical value $(7.23 \%)$ while the $\mathrm{C} \%$ could be due to the formation of amorphous carbon during the synthesis, as previously observed when using the UGR ${ }^{24}$. The crystallite size as obtained via Debye-Scherrer analysis shows smaller size for HfN nanoparticles and results are reported in Table 1.

Table 1. Experimental details of some representative samples obtained by varying $R$ and heating at different temperatures under nitrogen flow. Values of nominal diameter, as well as Elemental Analysis (EA) data and surface area are reported.

\begin{tabular}{|c|c|c|c|c|c|c|}
\hline \multirow{2}{*}{ Name } & \multirow{2}{*}{$\begin{array}{l}\text { Main Phase } \\
\text { (side } \\
\text { product) }\end{array}$} & \multicolumn{2}{|c|}{$\begin{array}{c}\text { Nominal } \\
\text { diameter }[\mathrm{nm}]\end{array}$} & \multicolumn{2}{|c|}{ EA [wt \%] } & \multirow{2}{*}{$\begin{array}{c}\text { Surface } \\
\text { area } \\
{\left[\mathrm{m}^{2} / \mathrm{g}\right]}\end{array}$} \\
\hline & & $\begin{array}{c}\text { by } \\
\text { XRD [a] }^{\text {[a }}\end{array}$ & $\begin{array}{c}\text { by } \\
\text { TEM }^{[b]}\end{array}$ & $\mathbf{N}^{[c]}$ & C & \\
\hline $\begin{array}{l}\text { Hf } \mathrm{R}=3 \\
900^{\circ} \mathrm{C}\end{array}$ & $\mathrm{Hf}_{2} \mathrm{ON}_{2}$ & 46 & $\begin{array}{c}10-30 \\
(55)\end{array}$ & 7.2 & 3.2 & 42 \\
\hline $\begin{array}{c}\text { Hf } R=10 \\
900^{\circ} \mathrm{C}\end{array}$ & $\mathrm{HfN}\left(\mathrm{Hf}_{2} \mathrm{ON}_{2}\right)$ & - & $5-25$ & 5.6 & 14.2 & 88 \\
\hline $\begin{array}{c}\text { Hf } R=16 \\
900^{\circ} \mathrm{C}\end{array}$ & $\mathrm{HfN}$ & 20 & $5-25$ & 5.8 & 21.2 & 45 \\
\hline $\begin{array}{l}\text { Hf } R=3 \\
1200^{\circ} \mathrm{C}\end{array}$ & $\mathrm{Hf}_{2} \mathrm{ON}_{2}$ & 69 & $13-42$ & 5.7 & 3.8 & 37 \\
\hline $\begin{array}{l}\mathrm{Hf} R=10 \\
1200^{\circ} \mathrm{C}\end{array}$ & $\mathrm{HfN}\left(\mathrm{Hf}_{2} \mathrm{ON}_{2}\right)$ & - & $7-21$ & 4.8 & 17.4 & - \\
\hline $\begin{array}{c}\text { Hf } R=16 \\
1200^{\circ} \mathrm{C}\end{array}$ & $\mathrm{HfN}$ & 25 & $5-15$ & 4.6 & 26.0 & 44 \\
\hline
\end{tabular}

[a]Calculated on the main peak in XRD using Scherrer equation. [b]Histograms reported in the $\mathrm{SI}$, values in bracket indicate that occasionally bigger particles were observed. [c] $\mathrm{N} \%$ theoretical value in both $\mathrm{Hf}_{2} \mathrm{ON}_{2}$ and $\mathrm{HfN}$ is $\sim 7 \%$.

Crystal structures of $\mathrm{HfN}, \mathrm{Hf}_{2} \mathrm{ON}_{2}$ and $\mathrm{HfO}_{2}$ are reported in figure 2 ( $\mathrm{HfN}$ is cubic, with unit cell parameter of $4.5120 \AA \mathrm{Hf}_{2} \mathrm{ON}_{2}$ has unit cell parameter of $\left.10.0634 \AA^{[31]}\right)$. 


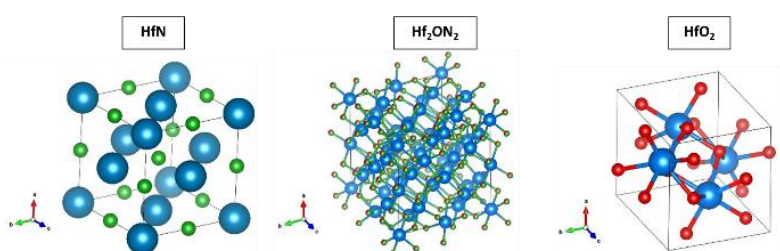

Figure 2. Crystal structures of $\mathrm{HfN}, \mathrm{Hf}_{2} \mathrm{ON}_{2}$ and $\mathrm{HfO}_{2}$. Cif file from ref. 36 and structures plotted using VESTA ${ }^{37}$.

To investigate the sample's morphology, larger scale homogeneity and particle dimensions, SEM and TEM analysis were performed. SEM images of $\mathrm{Hf}_{2} \mathrm{ON}_{2}$ prepared with an initial ratio $\mathrm{R}=3$ and treated at $900^{\circ} \mathrm{C}$ show clusters of uniform size and cube-like shape (Figure 3.A). The "edged" nature of the particles was also shown in some TEM images, where hexagonal shape nanoparticles are occasionally observed (highlighted in red in Figure 3.B). According to TEM, together with smaller nanoparticles (10-20 nm in diameter), clusters of bigger particles (50-60 nm) were also observed. TEM analysis confirmed the smaller size of the $\mathrm{HfN}$ nanoparticles over the $\mathrm{Hf}_{2} \mathrm{ON}_{2}$ ones (Figure 3.B-D and Figure SI.1) while SEM images of the same sample (Figure 3.C), display a needle-like shape, where nanoparticles seem to growth alongside a preferential orientation (2D structure).
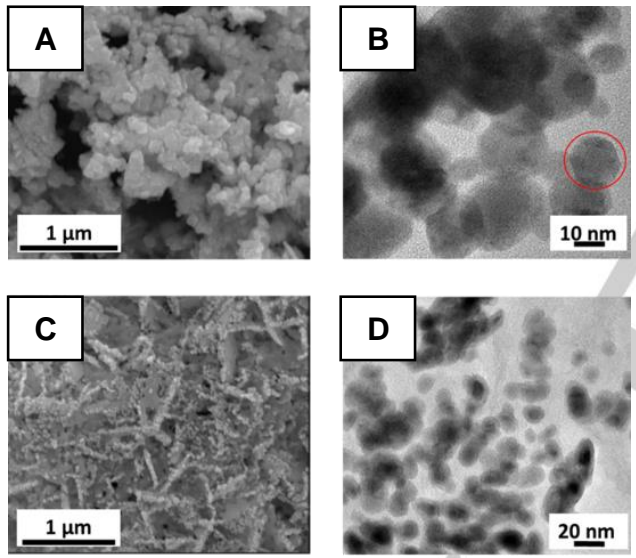

Figure 3. A) $S E M$ and $B$ ) TEM images of sample $R=3$ at $900^{\circ} \mathrm{C}$. C) $S E M$ and $D$ ) TEM images of sample $R=10$ treated at $1200^{\circ} \mathrm{C}$.

A closer examination of the TEM results performed on the same sample (Figure 3.D) evidenced the presence of small, core-shell interconnected nanoparticles. Overall, it can be concluded that the reaction conditions not only influence the final composition, but also the size and morphology of the final material. To further explore this point, additional samples were prepared with intermediate ratios, for which the TEM and SEM analysis were performed. From $R=10$ till $R=16$ the nanoparticles shape transforms from needle-like $(R=10)$ to rod-plate like $(R=12)$ to a layered structure for higher $\mathrm{R}(\mathrm{R}=16)$ as shown in Figure 4. From this figure, it can be also observed that the $2 \mathrm{D}$ structure, with the preferential growth direction, is completely lost for $R=16$, as also confirmed by TEM (Figure 5.A). An HR-TEM study also reveals a core-shell nature of the particles synthesised at $1200^{\circ} \mathrm{C}$ with $\mathrm{R}=16$
(Figure 5.B), where the crystalline core shows the (1-11) and (200) lattice planes for HfN (Figure 5.C) while the shell is amorphous. It must be noted that the shell is not observed for $\mathrm{R}<10$ or lower reaction temperature $\left(\mathrm{T}<900^{\circ} \mathrm{C}\right)$.
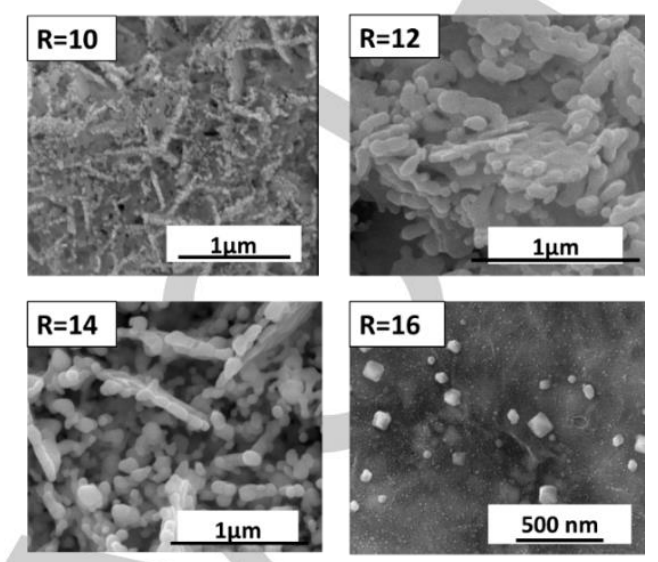

Figure 4. SEM images of $\mathrm{HfN}$ samples synthesised at $1200^{\circ} \mathrm{C}$ with different $\mathrm{R}$ (from 10 till 16).
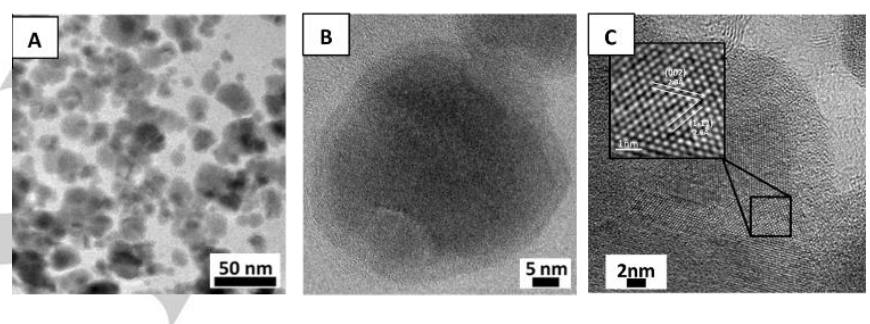

Figure 5. TEM images of $\mathrm{HfN}$ sample synthesised at $1200^{\circ} \mathrm{C}$ with $\mathrm{R}=16$ at increasing magnification. A) Overview of the nanoparticles. B) Single nanoparticle showing a core-shell structure and (c) HRTEM image showing the $\mathrm{d}$-spacing of the nanoparticle core.

XPS confirmed that the surface layer was oxygen-rich, which may be left after the conversion of the oxy-nitride phase in to the nitride one. The surface elemental composition (in wt.\%) is reported in Table 2, while a comparison of XPS spectra bands for the $\mathrm{Hf} 4 \mathrm{f}$, $\mathrm{N} 1 \mathrm{~s}, \mathrm{C} 1 \mathrm{~s}$ and $\mathrm{O} 1 \mathrm{~s}$ regions for each of the samples is shown in Figure 6. The fitted spectra, survey scans and peak assignment tables are shown in the supporting information (Figure SI.2-6 and Table SI.1-4).

Table 2. Elemental composition from XPS in wt.\% for the samples $\mathrm{HfO}_{2}$, $\mathrm{HfN}$ and $\mathrm{Hf}_{2} \mathrm{ON}_{2}$.

\begin{tabular}{|c|c|c|c|}
\cline { 1 - 2 } Element $\rightarrow$ & O 1s & N 1s & Hf 4f \\
\cline { 1 - 2 } $\begin{array}{c}\text { Compound } \\
\downarrow\end{array}$ & 16.88 & 2.23 & 45.9 \\
\cline { 1 - 3 } $\mathrm{HfO}_{2}$ & 14.95 & 4.04 & 48.61 \\
\cline { 1 - 3 } $\mathrm{Hf}_{2} \mathrm{ON}_{2}$ & 9.05 & 2.79 & 14.76 \\
\hline $\mathrm{HfN}$ & & & \\
\hline
\end{tabular}



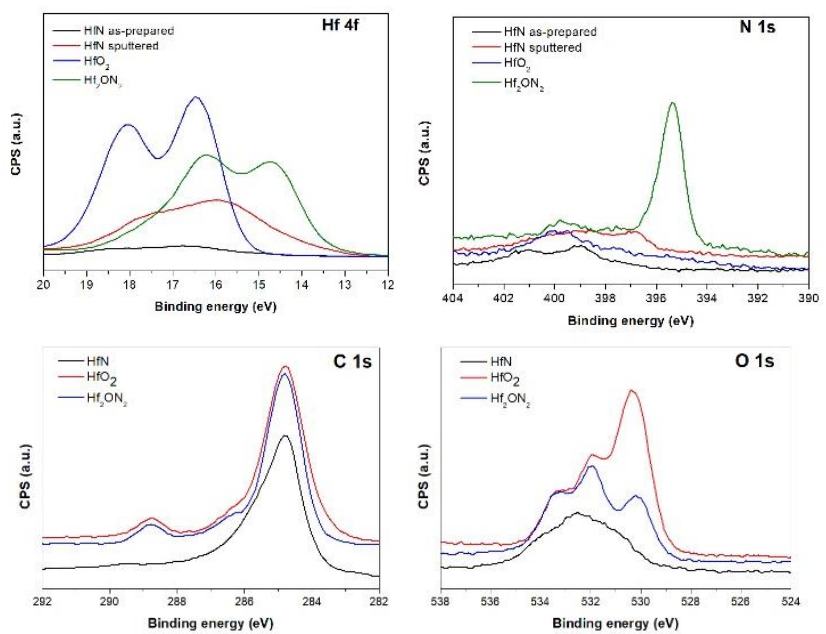

Figure 6. Comparison of XPS spectra of $\mathrm{HfO}_{2}, \mathrm{Hf}_{2} \mathrm{ON}_{2}$ and $\mathrm{HfN}$ (before and after sputtering) in $\mathrm{Hf} 4 \mathrm{f}, \mathrm{N} 1 \mathrm{~s}, \mathrm{C}$ 1s and $\mathrm{O}$ 1s regions.

$\mathrm{HfO}_{2}$ was confirmed from photoelectron peaks at 16.35 and 16.88 $\mathrm{eV}(\mathrm{Hf} 4 \mathrm{f} 7 / 2)$ agreeing well with previous characterisation results ${ }^{[32]}$. Lattice oxygen was also confirmed at $530.29 \mathrm{eV}(\mathrm{O} 1 \mathrm{~s}$ spectra $)^{[32]}$. A more reduced $\mathrm{Hf}$ species was observed in the oxynitride sample, with peaks at 14.66 and $16.01 \mathrm{eV}$ corresponding to $\mathrm{Hf}-\mathrm{N}$ and $\mathrm{Hf}-\mathrm{O}$ respectively ${ }^{[33,34]}$. The formation of the oxynitride phase was further established from the analysis of the core level $\mathrm{N}$ 1s spectra, where peaks in the 395-397 eV region were observed, corresponding to new $\mathrm{Hf}-\mathrm{N}$ bonds ${ }^{[20,33,35]}$. The HfN sample also showed oxidized $\mathrm{Hf}_{4} 4 / 2(16.65 \mathrm{eV})$ and $\mathrm{N}$ 1s at $401.34 \mathrm{eV}$, with the peak at $398.73 \mathrm{eV}$ assigned to the overlap of the $\mathrm{Hf} 4 \mathrm{p}$ plasmon. This is consistent with the oxygenrich outer shell of the nanoparticles, as observed by TEM on samples prepared with higher urea/metal molar ratio $(R)$. However, following etching of the sample under argon ion bombardment, the carbonaceous species was removed, and a new peak at $396.80 \mathrm{eV}$ was deconvoluted, corresponding to $\mathrm{Hf}-\mathrm{N}$ $[20,33,35]$. The binding energy of the $\mathrm{Hf} 4 \mathrm{f}$ peak also shifted from $16.65 \mathrm{eV}$ to $15.59 \mathrm{eV}$, further signifying the reduced $\mathrm{Hf}-\mathrm{N}$ species [33,34].

Electrochemical testing. The electrocatalytic performance was examined for both $\mathrm{Hf}_{2} \mathrm{ON}_{2}$ and $\mathrm{HfN}$. Commercial $\mathrm{HfO}_{2}$ and $\mathrm{RuO}_{2}$ were also tested to compare the OER activity. The OER activity in Fe-free electrolyte was initially tested in order to avoid iron contaminations on the working electrode, which would affect the results. This is a very important point to be considered, since it was reported that even small impurities of iron have an enormous effect on the OER activity of the catalysts ${ }^{[36]}$. In fact, a plethora of OER catalysts reported so-far are tested in non-purified electrolytes containing traces of Fe impurities but this does not allow to determine the actual catalytic activity of the material under investigation. Initially, the samples were deposited on glassy carbon electrodes to measure the intrinsic OER activities. CVs were repeated until a reproducible voltammogram was obtained. In addition, commercial $\mathrm{RuO}_{2}$, a benchmark catalyst for OER ${ }^{[1]}$, was used to compare the activity of our catalysts. The overpotential needed to achieve $10 \mathrm{~mA} / \mathrm{cm}^{2}$ current density was used as a parameter to compare different catalysts studied, herein. As shown in figure $8 \mathrm{~A}, \mathrm{RuO}_{2}$ requires, as expected, lowest overpotential $(321 \mathrm{mV})$ to achieve $10 \mathrm{~mA} / \mathrm{cm}^{2}$ catalytic current, followed by $\mathrm{HfN}(504 \mathrm{mV}), \mathrm{HfO}_{2}\left(497 \mathrm{mV}\right.$ at $\left.1 \mathrm{~mA} / \mathrm{cm}^{2}\right)$ and $\mathrm{Hf}_{2} \mathrm{ON}_{2}\left(577 \mathrm{mV}\right.$ at $\left.8 \mathrm{~mA} / \mathrm{cm}^{2}\right)$. The overpotential values are in line with those observed for widely studied $\mathrm{Ni}(\mathrm{OH})_{2}$ catalyst measured in Fe-free electrolytes ${ }^{[36]}$. The lower overpotential of $\mathrm{HfN}$ compared to $\mathrm{Hf}_{2} \mathrm{ON}_{2}$ and $\mathrm{HfO}_{2}$ can be attributed to better electrical conductivity of $\mathrm{HfN}^{[22]}$, which results in efficient charge transport. Tafel analysis was performed to gain insights on the mechanism underlying OER on our catalysts (figure 8B). The Tafel slope values are summarized in Table 3 which lie in the range of $130-300 \mathrm{mV} / \mathrm{dec}$ range for $\mathrm{HfN}$ and $\mathrm{Hf}_{2} \mathrm{ON}_{2}$ while a value of $385 \mathrm{mV} / \mathrm{dec}$ was obtained for $\mathrm{HfO}_{2}$. Next, we proceeded to measure the OER activity of our catalysts in normal commercially available $\mathrm{NaOH}$ electrolyte, which contains traces of $\mathrm{Fe}$ impurities, as this would be the obvious electrolyte of choice for commercial alkaline electrolysers. Figure $8 \mathrm{C}$ reports the $\mathrm{CVs}$ of the catalysts measured in $1 \mathrm{M} \mathrm{NaOH}$ electrolyte (non-purified). As can be seen, the OER current densities increased substantially for HfN and $\mathrm{Hf}_{2} \mathrm{ON}_{2}$, while $\mathrm{HfO}_{2}$ showed similar activity. The Tafel plots are reported in figure $8 \mathrm{D}$ and the slope values reported in table 4 indicate improved OER kinetics over $\mathrm{HfN}$ in the normal electrolyte. This is in line with the improvement observed for previously studied $\mathrm{Ni}(\mathrm{OH})_{2}$ catalysts $^{[36]}$.
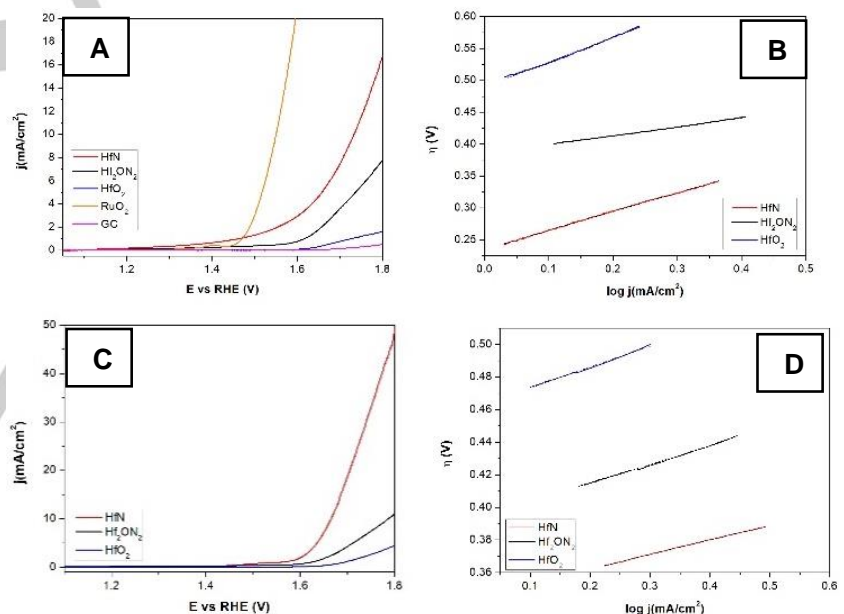

Figure 8. A) OER measurements using glassy carbon as supporting electrode the $\mathrm{CV}$ of glassy carbon is reported for comparison. B) Tafel plots comparison in $1 \mathrm{M} \mathrm{NaOH}$ purified electrolyte, C) OER measurements in $1 \mathrm{M} \mathrm{NaOH}$ (nonpurified) electrolyte and D) Tafel plots comparison in $1 \mathrm{M} \mathrm{NaOH}$ normal electrolyte for $\mathrm{HfN}$, is $\mathrm{Hf}_{2} \mathrm{ON}_{2}$ and $\mathrm{RuO}_{2}$. The dashed black lines represent the linear fitting to calculate Tafel slopes.

To better understand the reason behind the good performance of $\mathrm{HfN}$ as compared to $\mathrm{Hf}_{2} \mathrm{ON}_{2}$, double layer capacitance $\left(\mathrm{C}_{\mathrm{dl}}\right)$ measurements were performed to determine their electrochemically active surface area (ECSA), following the procedure reported in literature ${ }^{[37]}$. The $\mathrm{CV}$ s for this purpose were measured in the range of $0-0.1 \mathrm{~V}$ vs $\mathrm{Ag} / \mathrm{AgCl}$ where no faradic charge transfer occurred (See figure SI. 7). Despite having nearly similar $\mathrm{C}_{\mathrm{dl}}$ values (figure $\mathrm{SI} .8$.), $\mathrm{HfN}$ showed much higher activity for OER as compared to $\mathrm{Hf}_{2} \mathrm{ON}_{2}$, indicating higher intrinsic activity of $\mathrm{HfN}$ towards this reaction. The $\mathrm{Cdl}$ values for $\mathrm{HfO}_{2}$ were three 
orders of magnitude lower than that of $\mathrm{HfN}$, indicating lower ECSA of the former (see figure SI. 8). This, combined with the insulating nature of $\mathrm{HfO}_{2}$, might be the cause for the lowest OER activity of $\mathrm{HfO}_{2}$. This highlights that the catalyst having high conductivity with high ECSA is required to achieve high OER activity and that presence of $\mathrm{Fe}$ impurity only cannot guarantee the high OER activity.

This is further supported by our electrochemical impedance spectroscopy (EIS) measurements. Nyquist plots of the impedance data are reported in figure 9 , both for the purified and normal electrolyte. All the catalysts studied herein exhibit a single semicircle, which is related to the charge transfer resistance $\left(R_{c t}\right)$ associated with OER process. The size of the semicircle in the low-frequency range increases from $\mathrm{HfN}<\mathrm{Hf}_{2} \mathrm{ON}_{2}<\mathrm{HfO}_{2}$, indicating that OER is most favoured on $\mathrm{HfN}$ electrodes and least favoured on $\mathrm{HfO}_{2}$ electrodes ${ }^{[38]}$. Furthermore, in normal electrolytes, the trend in $R_{c t}$ values remains the same while the values decrease considerably in all the cases as shown in Table 4. This further highlights the efficient OER over $\mathrm{HfN}$ in both purified and normal electrolytes.
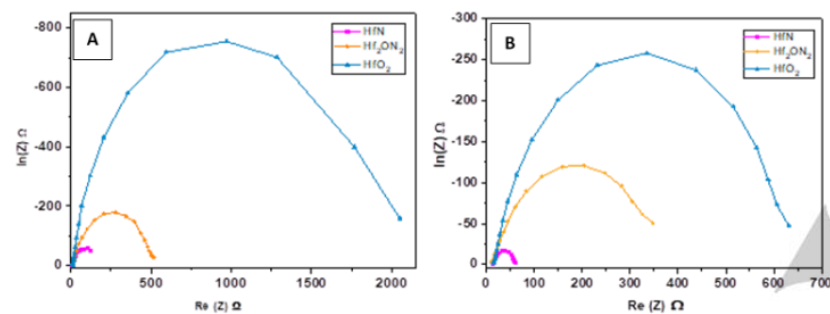

Figure 9. Nyquist plots of $\mathrm{HfN}, \mathrm{Hf}_{2} \mathrm{ON}_{2}$ and $\mathrm{HfO}_{2}$ at $1.72 \mathrm{~V}$ vs $\mathrm{RHE}$ in A) purified $1 \mathrm{M} \mathrm{NaOH}$ and $\mathrm{B}$ ) in normal $1 \mathrm{M} \mathrm{NaOH}$.

In order to further maximize the OER catalytic activity of $\mathrm{HfN}$, we deposited the catalyst ink on $\mathrm{Ni}$ foam, a support with uniform three-dimensional network, high surface area and good electron transport ${ }^{[39]}$. As can be seen from the polarization curves reported in Figure 10, OER currents improved significantly in both purified and normal electrolytes. The HfN-NF catalyst achieves 10 $\mathrm{mA} / \mathrm{cm}^{2}$ of OER current at an overpotential of only $391 \mathrm{mV}$ in purified electrolyte, while in the normal electrolyte this value further improves to $358 \mathrm{mV}$. The Tafel slope values also improve in both cases indicating better kinetics of OER on $\mathrm{HfN}$ on porous 3D NF substrate. The overpotential values obtained here are comparable to those of the widely studied $\mathrm{Ni}$ and Co-based catalysts and could be further improved by increasing ECSA of the $\mathrm{HfN}$ catalyst ${ }^{[7]}$. A comparison of the overpotential and Tafel slope values for the tested $\mathrm{HfN}$ with other nitrides-based catalysts reported in literature and tested in similar conditions is reported in figure SI.6.
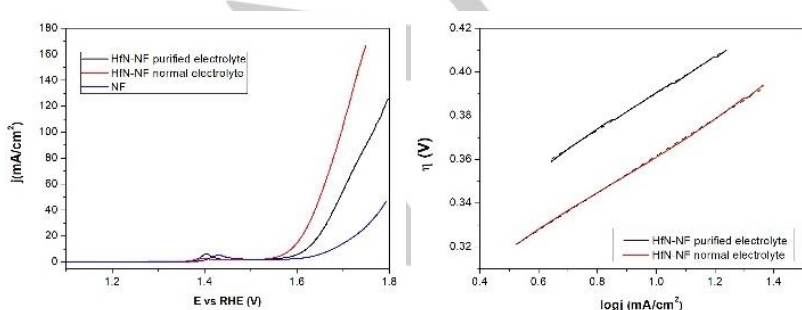

Figure 10. A) OER measurements in $1 \mathrm{M} \mathrm{NaOH}$ purified and non-purified electrolyte, using nickel foam (NF) as support for HfN. The CV of Nickel foam is shown for comparison. B) Tafel plots comparison for HfN, on nickel foam (NF), measured both in the normal and in the purified electrolyte. The dashed black lines represent the linear fitting to calculate Tafel slopes.

Table 3. Over potential, Tafel slope and average $\mathrm{Cd}$ values for the $\mathrm{HfN}, \mathrm{Hf}_{2} \mathrm{ON}_{2}$ and $\mathrm{HfO}_{2}$ catalysts, tested with different supports both in the normal and in the purified electrolyte.

\begin{tabular}{|c|c|c|c|}
\hline Catalyst & $\begin{array}{c}\text { Over potential } \\
(\mathrm{mV}) \text { at } 10 \\
\mathrm{~mA} / \mathrm{cm}^{2}\end{array}$ & $\begin{array}{c}\text { Tafel slope } \\
\text { (mV/dec) }\end{array}$ & $\begin{array}{c}\text { Average } \\
\mathrm{C}_{\mathrm{d}} \\
\left(\mathrm{mF} / \mathrm{cm}^{2}\right)\end{array}$ \\
\hline $\begin{array}{l}\mathrm{HfN}(\mathrm{GC}) \\
\text { purified } \\
\text { electrolyte }\end{array}$ & $504 \mathrm{mV}$ & 295 & 0.0013 \\
\hline $\begin{array}{l}\mathrm{HfN}(\mathrm{GC}) \\
\text { normal } \\
\text { electrolyte }\end{array}$ & $436 \mathrm{mV}$ & 89 & \\
\hline $\begin{array}{c}\mathrm{Hf}_{2} \mathrm{ON}_{2}(\mathrm{GC}) \\
\text { purified } \\
\text { electrolyte }\end{array}$ & $\begin{array}{l}577 \mathrm{mV} \text { (at } \\
8 \mathrm{~mA} / \mathrm{cm} 2)\end{array}$ & 139 & 0.0014 \\
\hline $\begin{array}{c}\mathrm{Hf}_{2} \mathrm{ON}_{2}(\mathrm{GC}) \\
\text { normal } \\
\text { electrolyte }\end{array}$ & $557 \mathrm{mV}$ & 115 & \\
\hline $\begin{array}{c}\mathrm{HfO}_{2}(\mathrm{GC}) \\
\text { purified } \\
\text { electrolyte }\end{array}$ & $\begin{array}{l}497 \mathrm{mV} \text { (at } \\
1 \mathrm{~mA} / \mathrm{cm} 2)\end{array}$ & 385 & $3.9 * 10^{-5}$ \\
\hline $\begin{array}{c}\mathrm{HfO}_{2}(\mathrm{GC}) \\
\text { normal } \\
\text { electrolyte }\end{array}$ & $\begin{array}{l}585 \mathrm{mV} \text { (at } \\
5 \mathrm{~mA} / \mathrm{cm} 2)\end{array}$ & 128 & \\
\hline $\begin{array}{l}\mathrm{HfN}(\mathrm{NF}) \\
\text { purified } \\
\text { electrolyte }\end{array}$ & $391 \mathrm{mV}$ & 84 & \\
\hline $\begin{array}{l}\text { HfN (NF) } \\
\text { normal } \\
\text { electrolyte }\end{array}$ & $358 \mathrm{mV}$ & 85 & \\
\hline
\end{tabular}

Table 4. Charge transfer resistance values for the $\mathrm{HfN}, \mathrm{Hf}_{2} \mathrm{ON}_{2}$ and $\mathrm{HfO}_{2}$ catalysts, both in the normal and in $1 \mathrm{M} \mathrm{NaOH}$ purified electrolyte.

\begin{tabular}{|c|c|c|}
\hline \multirow{2}{*}{ Sample } & \multicolumn{2}{|c|}{ Rct $(\Omega)$} \\
\cline { 2 - 3 } & Purified electrolyte & Normal electrolyte \\
\hline $\mathrm{HfN}$ & 110 & 47 \\
\hline $\mathrm{Hf}_{2} \mathrm{ON}_{2}$ & 505 & 338 \\
\hline $\mathrm{HfO}_{2}$ & 2039 & 618 \\
\hline
\end{tabular}

Finally, the stability of the HfN catalyst was measured under OER operating conditions at a constant applied current density of 10 $\mathrm{mA} / \mathrm{cm}^{2}$ for $24 \mathrm{~h}$ as reported in figure 11 . From this figure, it can be appreciated that the potential required to maintain the applied current density remains nearly constant through the $24 \mathrm{~h}$ indicating excellent stability of our HfN catalyst. 


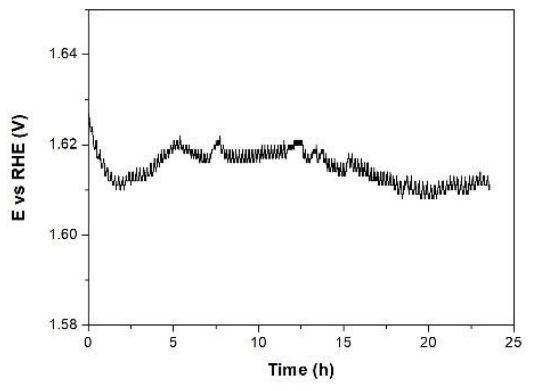

Figure 11. Chronopotentiometry measurement of HfN sample on NF, measured at $10 \mathrm{~mA} / \mathrm{cm}^{2}$.

The morphology (via TEM) and composition (via PXRD) of the $\mathrm{HfN}$ catalyst was examined after the stability tests. As shown in figure SI.9-11 and table SI.5, no significant changes were observed, further confirming the stability of our HfN catalyst.

\section{Conclusion}

Well-defined and small nanoparticles of $\mathrm{Hf}_{2} \mathrm{ON}_{2}$ and $\mathrm{HfN}$ were prepared and tested for the first time for OER. An extensive characterization was made before and after testing, using powder XRD, SEM, HR-TEM and XPS. The OER performance of $\mathrm{Hf}_{2} \mathrm{ON}_{2}$ and $\mathrm{HfN}$ were compared in $\mathrm{Fe}$-free purified and normal electrolyte $(1 \mathrm{M} \mathrm{NaOH})$, using both glassy carbon and nickel foam as supports, to determine the actual catalytic activity of the materials under investigation. HfN showed the best activity, attributed to its high electrical conductivity, favouring an efficient charge transport. The HfN catalyst achieved, $10 \mathrm{~mA} / \mathrm{cm}^{2}$ of OER current at an overpotential of only $391 \mathrm{mV}$ and $358 \mathrm{mV}$ in purified and normal electrolyte, respectively, with a Tafel slope of 84 and $85 \mathrm{mV} / \mathrm{dec}$. Long-term stability for $24 \mathrm{~h}$ of $\mathrm{HfN}$ under OER operating conditions at a constant current density of $10 \mathrm{~mA} / \mathrm{cm}^{2}$ was tested and the potential remained nearly constant indicating excellent stability of our $\mathrm{HfN}$ catalyst. The stability was further confirmed by PXRD and TEM done on the catalysts after OER test. The results presented so far place the system among the most promising catalyst for OER tested to date, in term of sustainability, activity and stability.

\section{Experimental Section}

Nanoparticles preparation. In a typical experiment, hafnium (IV) chloride $\left(\mathrm{HfCl}_{4}, \mathrm{VWR} 98+\%\right) /$ methanol solutions (1.24M) were prepared and added with suitable amounts of urea $\left(\mathrm{CO}\left(\mathrm{NH}_{2}\right)_{2}\right.$, Sigma Aldrich $\left.99 \%\right)$ to reach a final urea/ $/ \mathrm{HCl}_{4}$ molar ratio (R) from 1 to 16 . Mixtures were stirred till a clear viscous yet transparent solution was observed (Fig.12 A). The gel-like precursor was then thermally treated under $\mathrm{N}_{2}$ flow up to $1200^{\circ} \mathrm{C}$ for $3 \mathrm{~h}$ and thereafter cooled to room temperature. The final product was a fine powder, light grey for samples treated up to $900^{\circ} \mathrm{C}$ (Fig.12 B) and dark grey for the ones treated up to $1200^{\circ} \mathrm{C}$ (Fig. $12 \mathrm{C}$ ). For comparison, $\mathrm{HfO}_{2}$ was also prepared via UGR, using a mixed flow of $\mathrm{N}_{2}$ and air. The usefulness of the UGR to prepare metal oxides was also previously reported $^{[40]}$
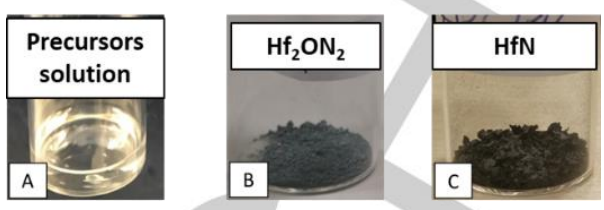

Figure 12. Photographs showing the precursor solution (A), the final product obtained after heat treatment under $\mathrm{N}_{2}$ flow at $900{ }^{\circ} \mathrm{C}$ (B) and $1200^{\circ} \mathrm{C}(\mathrm{C})$, respectively. Phase attribution was made by PXRD study (see text for details).

Electrochemical measurements. The prepared $\mathrm{HfN}$ and $\mathrm{Hf}_{2} \mathrm{ON}_{2}$ were tested for OER using IVIUM Compactstat potentiostat and their performances compared with those of commercial $\mathrm{HfO}_{2}$ (Sigma Aldrich, 98\%) and $\mathrm{RuO}_{2}$ (Sigma Aldrich, 99.9\%). The catalyst ink was prepared grounding in a mortar $2.5 \mathrm{mg}$ of the powder catalyst and then adding 100 microliters of Nafion $\Theta$ solution, $0.25 \%$ in ethanol ( 5 wt \% in lower aliphatic alcohols and $15-20 \%$ water, Sigma Aldrich). For the catalysts deposited on glassy carbon substrates, conductive carbon black was added (carbon black super P Alfa-Aesar, 99+\%). The ink was ultrasonicated for $30 \mathrm{~min}$ and then drop-cast with different loadings on different electrode support, e.g. glassy carbon ( $3 \mathrm{~mm}$ diameter) and nickel foam (Sigma Aldrich, 95\%, foam, thickness $1.6 \mathrm{~mm}$, bulk density $0.45 \mathrm{~g} / \mathrm{cm}^{3}$, porosity $95 \%$ ) and allowed to dry at room temperature in ambient air. The loading for each catalyst was optimized to obtain maximum OER activity. The best ink loading was found to be $5 \mu \mathrm{l}$ for $\mathrm{Hf}_{2} \mathrm{ON}_{2}\left(1.96 \mathrm{mg} / \mathrm{cm}^{2}\right), 10 \mu \mathrm{l}$ for $\mathrm{HfN}$ $\left(4.57 \mathrm{mg} / \mathrm{cm}^{2}\right)$ and $20 \mu \mathrm{l}$ for $\mathrm{HfO}_{2}\left(7.8 \mathrm{mg} / \mathrm{cm}^{2}\right)$. OER measurements were conducted using a three-electrode cell set-up, using a double junction $\mathrm{Ag} / \mathrm{AgCl}(3.8 \mathrm{M} \mathrm{KCl})$ as a reference electrode and platinum wire as counter electrode. Cyclic voltammetry (CV) measurements were performed in $1 \mathrm{M}$ $\mathrm{NaOH}$ electrolyte (Sigma Aldrich, $>98 \%$, diluted with Milli-Q water, 18.2 $\mathrm{m} \Omega \mathrm{cm}$ at $25^{\circ} \mathrm{C}$ ) at room temperature in the range of $0-0.8 \mathrm{~V}(\mathrm{vs} \mathrm{Ag} / \mathrm{AgCl})$ with a scan rate of $5 \mathrm{mV} /$ second. Impedance measurements were performed in the frequency range from $0.1 \mathrm{~Hz}$ to $1 \mathrm{MHz}$. All data were iRcorrected using iR correction function of IVIUM software. The potentials were converted to RHE (reversible hydrogen electrode) scale by using the following formula: $E_{\mathrm{RHE}}=\mathrm{E}^{0} \mathrm{Ag} / \mathrm{AgCl}+\mathrm{E}_{\mathrm{Ag} / \mathrm{AgCl}}+(0.059 \times \mathrm{pH})$. Long-term stability measurement was conducted by chronopotentiometry at an applied current density of $10 \mathrm{~mA} / \mathrm{cm}^{2}$.

Electrolyte purification. Iron-free electrolyte was obtained following the procedure reported by Trotochaud et al.. ${ }^{[36]}$, briefly, $2 \mathrm{~g}$ of Ni($\left(\mathrm{NO}_{3}\right)_{2}{ }^{*} 6 \mathrm{H}_{2} \mathrm{O}$ (Sigma Aldrich, 99.999\%) were dissolved, using a centrifuge tube, in few $\mathrm{ml}$ of water (Milli-Q water, $18.2 \mathrm{~m} \Omega \mathrm{cm}$ at $25^{\circ} \mathrm{C}$ ), followed by the addition of $20 \mathrm{ml}$ of $1 \mathrm{M} \mathrm{NaOH}$. This resulted in the precipitation of green coloured $\mathrm{Ni}(\mathrm{OH})_{2}$. The mixture underwent several cycles of centrifuging and supernatant removal, adding a fresh mixture of $20 \mathrm{ml}$ water/ $1 \mathrm{ml} 1 \mathrm{M} \mathrm{NaOH}$ every time. After several washings, the tube was filled with $1 \mathrm{M} \mathrm{NaOH}$, shaken and left overnight. The purified electrolyte was then used for OER testing in Fe free conditions. 


\section{Acknowledgements}

C.G. and C.D. acknowledge QMUL for financial support. All authors acknowledge Dr. M. Prato (Materials Characterization Facility - Istituto Italiano di Tecnologia) for support in XPS data acquisition and Mr Maurizio Leo from Nanoforce Technology Ltd for his kind help during materials preparation.

Keywords: hafnium nitride, hafnium oxide, hafnium oxynitride, nanoparticles, nitrides, oxygen evolution reaction (OER), Urea Glass Route.

[1] N.-T. Suen, S.-F. Hung, Q. Quan, N. Zhang, Y.-J. Xu, H. M. Chen, Chemical Society Reviews 2017, 46, 337-365.

[2] Y. Zheng, Y. Jiao, M. Jaroniec, S. Z. Qiao, Angewandte Chemie International Edition 2015, 54, 52-65.

[3] Y. Lee, J. Suntivich, K. J. May, E. E. Perry, Y. Shao-Horn, The Journal of Physical Chemistry Letters 2012, 3, 399404.

[4] D. V. Shinde, L. D. Trizio, Z. Dang, M. Prato, R. Gaspari, L. Manna, Chemistry of Materials 2017, 29, 7032-7041.

[5] M. Li, Y. Zhu, H. Wang, C. Wang, N. Pinna, X. Lu, Advanced Energy Materials 2019, 9, 1803185.

[6] M. Wang, Z. Dang, M. Prato, D. V. Shinde, L. De Trizio, L. Manna, ACS Applied Nano Materials 2018, 1, 5753-5762.

[7] M. Tahir, L. Pan, F. Idrees, X. Zhang, L. Wang, J.-J. Zou, Z. L. Wang, Nano Energy 2017, 37, 136-157.

[8] D. H. Youn, S. Han, J. Y. Kim, J. Y. Kim, H. Park, S. H. Choi, J. S. Lee, ACS Nano 2014, 8, 5164-5173.

[9] D. H. Youn, G. Bae, S. Han, J. Y. Kim, J.-W. Jang, H. Park, S. H. Choi, J. S. Lee, Journal of Materials Chemistry $A$ 2013, 1, 8007.

[10] R. B. Levy, M. Boudart, Science 1973, 181, 547-549.

[11] L. Ma, L. R. L. Ting, V. Molinari, C. Giordano, B. S. Yeo, J. Mater. Chem. A 2015, 3, 8361-8368.

[12] U. Joshi, J. Lee, C. Giordano, S. Malkhandi, B. S. Yeo, Physical Chemistry Chemical Physics 2016, 18, 2154821553.

[13] N. Han, P. Liu, J. Jiang, L. Ai, Z. Shao, S. Liu, Journal of Materials Chemistry A 2018, 6, 19912-19933.

[14] F. Yu, H. Zhou, Z. Zhu, J. Sun, R. He, J. Bao, S. Chen, Z. Ren, ACS Catalysis 2017, 7, 2052-2057.

[15] M. Shao, Q. Chang, J.-P. Dodelet, R. Chenitz, Chemical Reviews 2016, 116, 3594-3657.

[16] A. Leineweber, R. Niewa, H. Jacobs, W. Kockelmann, Journal of Materials Chemistry 2000, 10, 2827-2834.

[17] L. Cao, Y. Yu, S. Huang, yanpeng li, stephan N. steinmann, W. Yang, Nano Lett. 2014, 14, 2, 553-558.

[18] D. Ham, J. Lee, Energies 2009, 2, 873-899.

[19] M. Chisaka, Y. Suzuki, T. lijima, Y. Ishihara, R. Inada, Y. Sakurai, ECS Electrochemistry Letters 2012, 1, F4-F8.

[20] M. Chisaka, H. Muramoto, ChemElectroChem 2014, 1 , 863-867.

[21] X. Yang, F. Zhao, Y.-W. Yeh, R. S. Selinsky, Z. Chen, N. Yao, C. G. Tully, Y. Ju, B. E. Koel, Nature Communications 2019, 10, 1543.

[22] Y. Zhong, X. Xia, F. Shi, J. Zhan, J. Tu, H. J. Fan, Advanced Science 2016, 3, 1500286.

[23] Y. Abghoui, A. L. Garden, J. G. Howalt, T. Vegge, E. Skúlason, ACS Catalysis 2016, 6, 635-646.

[24] 2019.

[25] S. Karwal, M. A. Verheijen, B. L. Williams, T. Faraz, W. M. M. Kessels, M. Creatore, Journal of Materials Chemistry $C$ 2018, 6, 3917-3926.
[26] C. Giordano, C. Erpen, W. Yao, M. Antonietti, Nano Letters 2008, 8, 4659-4663.

[27] C. Giordano, C. Erpen, W. Yao, B. Milke, M. Antonietti, Chemistry of Materials 2009, 21, 5136-5144.

[28] Q. Gao, S. Wang, Y. Ma, Y. Tang, C. Giordano, M. Antonietti, Angewandte Chemie International Edition 2012, 51, 961-965.

[29] B. Milke, C. Wall, S. Metzke, G. Clavel, M. Fichtner, C. Giordano, Journal of Nanoparticle Research 2014, 2895.

[30] C. Giordano, A. Kraupner, I. Fleischer, C. Henrich, G. Klingelhöfer, M. Antonietti, Journal of Materials Chemistry 2011, 21, 16963.

[31] The "Inorganic Crystal Structure Database (ICSD)," can be found under http://www2.fiz-karlsruhe.de/icsd_web.html.

[32] D. Barreca, A. Milanov, R. A. Fischer, A. Devi, E. Tondello, Surface Science Spectra 2007, 14, 34-40.

[33] M. Lee, Z.-H. Lu, W.-T. Ng, D. Landheer, X. Wu, S. Moisa, Applied Physics Letters 2003, 83, 2638-2640.

[34] Y.-H. Chou, H.-T. Chiu, T.-F. Kuo, C.-C. Chi, S.-H. Chuang, Applied Physics Letters 2006, 89, 252901.

[35] A. Arranz, C. Palacio, Surface Science Spectra 2004, 11, 33-42.

[36] M. S. Burke, M. G. Kast, L. Trotochaud, A. M. Smith, S. W. Boettcher, Journal of the American Chemical Society 2015, 137, 3638-3648.

[37] G. Li, L. Anderson, Y. Chen, M. Pan, P.-Y. Abel Chuang, Sustainable Energy \& Fuels 2018, 2, 237-251.

[38] H. Ma, C. Liu, J. Liao, Y. Su, X. Xue, W. Xing, Journal of Molecular Catalysis A: Chemical 2006, 247, 7-13.

[39] C. Walter, P. W. Menezes, S. Orthmann, J. Schuch, P. Connor, B. Kaiser, M. Lerch, M. Driess, Angewandte Chemie International Edition 2018, 57, 698-702.

[40] F. Armetta, M. L. Saladino, C. Giordano, C. Defilippi, Ł. Marciniak, D. Hreniak, E. Caponetti, Scientific Reports 2019, 9, 3368. 


\section{Entry for the Table of Contents}

\section{RESEARCH ARTICLE}

HfN nanoparticles prepared via UGR are highly active and stable electrocatalyst for the water splitting semireaction OER (Oxygen Evolution Reaction). The results presented place HfN amongst one of the most promising catalysts for OER tested to date, in term of sustainability, activity and stability.

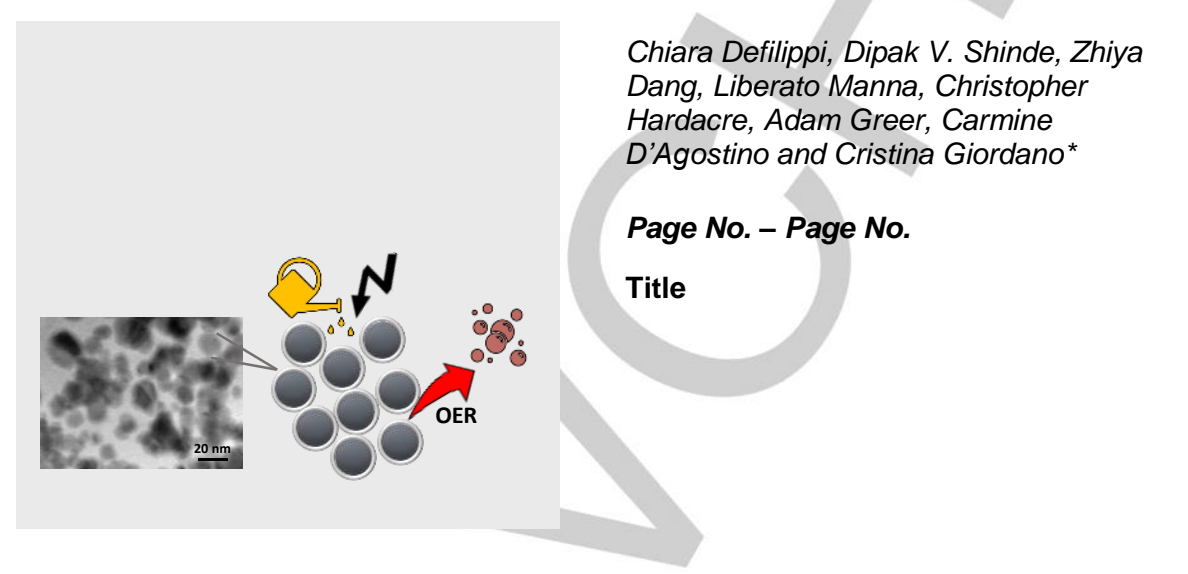

